\section{REFLEXIONES ESTUDIANTILES}

\author{
Johana ANDREA Jiménez Robles \\ Fundación Universitaria Los Libertadores \\ Colombia \\ [jajimenez1@libertadores.edu.co]
}

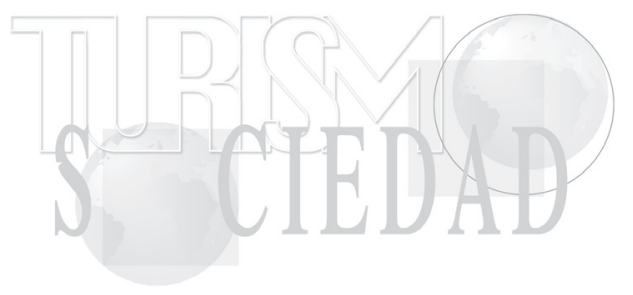

TURISMO SOLIDARIO Y COMUNITARIO EN CHAGUANÍ Y PULÍ, CUNDINAMARCA, UNA ALTERNATIVA ECONÓMICA SUSTENTABLE 1

\section{SOLIDARY AND COMMUNITY \\ TOURISM IN CHAGUANÍ \\ AND PULÍ, CUNDINAMARCA, AND ECONOMIC SUSTAINABLE \\ ALTERNATIVE}

1 Fecha de recepción: 6 de octubre de 2015

Fecha de modificación: 20 de febrero de 2016

Fecha de aceptación: 31 de mayo de 2016

Para citar el artículo: Jiménez, J. (2016). Turismo solidario y comunitario en Chaguaní y Pulí, Cundinamarca, una alternativa económica sustentable. Turismo y Sociedad, XX, pp. 249-263. DOI: https://doi.org/10.18601/01207555.n20.14

\section{Resumen}

Este artículo muestra el proceso para el desarrollo de un producto turístico con dos formas de gestión que en Colombia no se desarrollan conjuntamente: turismo solidario y comunitario, siendo estos similares, ya que generan un desarrollo económico de las poblaciones con altos índices NBI (necesidades básicas insatisfechas) y promueven la conservación y preservación del patrimonio cultural y natural.

Para el desarrollo del estudio se utilizaron dos metodologías: exploratoria, siendo el turismo solidario un tema poco estudiado en Colombia, y descriptiva, ya que se analizaron características de las comunidades seleccionadas. Se observa que existe una población con altos índices de NBI y con interés en superarlos aprovechando su riqueza natural y cultural, además de una demanda interesada en aportar en proyectos que beneficien a terceros. Es así que se plantearon dos subproductos bajo un producto "paraguas" y estrategias acompañadas de programas que permitan el desarrollo de este.

Palabras claves: Población, pobreza, patrimonio, turismo comunitario, turismo solidario, conservación y preservación, alternativa económica, sustentable.

\begin{abstract}
The process appears for the development of a tourist product, with two forms of management that in Colombia don't develop together; solidary and community tourism, being these similar since they generate an economic development of the populations with high indexes NBI (basic unsatisfied needs) and promote the conservation and preservation of the cultural and natural heritage.

For the development of the study two methodologies were in use, Exploratory being the solidary tourism, a topic little studied in Colombia and descriptive, since there were analyzed characteristics of the selected communities. Is observed that a population
\end{abstract}


exists with NBI high indexes and with interest to overcome them taking advantage of his natural and cultural wealth and a demand interested in reaching in projects that they benefit to others. It is so two by-products appeared under a product umbrella, besides strategies and programs that allow the development of be.

Keywords: Population, poverty, heritage, community tourism, solidary tourism, conservation and preservation, economical alternative, sustainable.

\section{Introducción}

El presente artículo muestra parte del proceso llevado a cabo durante la investigación que se desarrolló debido a la siguiente formulación de problema: ¿es posible generar una alternativa económica sustentable con el desarrollo de un producto turístico para los territorios de Chaguaní y Pulí? Tal pregunta surgió al buscar una alternativa por medio del desarrollo de un producto de turismo solidario y comunitario en la provincia de Magdalena Centro, siendo esta una de las provincias con mayor índice de pobreza en Cundinamarca y que cuenta con siete municipios, a saber: Beltrán, Bituima, Chaguaní, Guayabal de Síquima, Pulí, San Juan de Rioseco y Vianí.

Se planteó -justamente con estas formas de gestión del turismo- la creación de una alternativa económica sustentable que mitigue el alto índice de pobreza en la provincia y utilice la riqueza en recursos naturales y culturales, para así poder generar ingresos y beneficios a la comunidad por medio de la preservación y conservación del patrimonio natural y cultural.

Al desarrollar la investigación, se encontró que en Colombia no se han desarrollado estudios que incluyan esta forma de gestión del turismo, lo que generó la necesidad de adelantar investigaciones que mostraron la existencia de una oferta y una demanda, las cuales participarían en la ejecución de proyectos en beneficio de la comunidad mediante la convivencia y el aprendizaje de sus riquezas culturales y naturales.

Para el desarrollo del trabajo se preseleccionaron tres municipios de la provincia teniendo en cuenta la formulación del problema y el principal resultado que busca. Por tal razón, según datos del DANE, los municipios con mayores índices de pobreza dentro de la provincia de Magdalena Centro son Chaguaní, Pulí y Bituima. Al verificar las características de turismo solidario y comunitario, Bituima fue descartada para la investigación.

Según The Internacional Centre for Responsable Tourism (citado por Cañamás, 2011), el turismo solidario se encuentra compuesto por tres dimensiones:

- Dimensión económica. Esta busca beneficiar a las comunidades menos favorecidas con la actividad neta del turismo por medio del apoyo a las pequeñas infraestructuras del turismo que serán totalmente regidas por la población local.

- Dimensión sociocultural. Las comunidades receptoras serán las protagonistas de esta clase de turismo, por medio del cual se busca que el turista se acople y conozca su cultura, tradiciones, formas de vida, etc. De esta manera se pretende generar el menor impacto en estas comunidades y hacer que estas se lleven una idea de la importancia del cuidado y la preservación de estas culturas para las generaciones futuras.

- Así, entonces, la tercera dimensión del turismo solidario se enfoca en tener en cuenta al medio ambiente desde el punto de vista de la conservación y la preserva- 
ción, ya que existe un turismo de masas que ha dañado el medio ambiente de una forma irreparable. Como consecuencia de esto, se busca contrarrestar el impacto negativo de este turismo con la nueva tendencia del turismo sostenible.

Estas tres dimensiones del turismo solidario están completamente relacionadas con los principios del turismo comunitario, a saber: socialmente solidario, ambientalmente responsable, principio económico y principio cultural.

Al empalmar las características, y luego de descartar a Bituima, se procedió a realizar el levantamiento del inventario turístico y el acercamiento a los municipios preseleccionados, "Chaguaní y Pulí", seguido por el contacto y la aceptación de las juntas de acción comunal.

Tal investigación arrojó dos subproductos bajo el producto "paraguas" de turismo de naturaleza, en el que "el turismo de naturaleza y el ecoturismo" se reconocen como formas de turismo particularmente enriquecedoras, siempre que respeten el patrimonio natural y a la población local y se ajusten a la capacidad de ocupación de los lugares turísticos (Organización Mundial del Turismo, 1999, citado del Ministerio de Comercio Industria y Turismo, 2012).

Durante el trabajo de campo realizado se percibió la falta de inversión en proyectos turísticos, ya que en los planes de desarrollo no existía un ítem que mencionara el apoyo económico o intelectual hacia el turismo, generando así el desconocimiento de la comunidad hacia esta alternativa económica sustentable y evitando, por medio de esta alternativa, hacer una recopilación de su patrimonio cultural perdido por la migración de la población a causa de los conflictos armados vividos en años anteriores.
Es por esto que bajo la propuesta de los subproductos se estableció un ejemplo de paquete turístico como primer paso para la generación del turismo, para que, por medio de la recopilación realizada, la comunidad tuviera una idea de qué atractivos están disponibles para un visitante. Para llevar a cabo la difusión y el reconocimiento de los subproductos y el paquete turístico, se plantearon diferentes estrategias y programas que al desarrollarse con éxito permitirán que el trabajo sea llevado a cabo en otros municipios de Colombia y generar así alternativas sustentables que superen los altos índices NBI.

\section{Metodología y desarrollo}

El proyecto se realizó bajo dos tipos de estudio: exploratorio y descriptivo. Según Dankhe (1986, citado por Hernández-Sampieri, Fernández-Collado y Baptista-Lucio, 1997), "los estudios exploratorios se efectúan, normalmente, cuando el objetivo es examinar un tema o problema de investigación poco estudiado o que no ha sido abordado antes" y los estudios descriptivos buscan "especificar las propiedades importantes de personas, grupos, comunidades o cualquier otro fenómeno que sea sometido a análisis".

Así mismo, el proyecto fue un estudio de tipo exploratorio, ya que el turismo solidario y el comunitario no se han desarrollado conjuntamente en Colombia ni han sido estudiados ampliamente en Cundinamarca. Este tipo de investigación dispuso el camino para continuar con el estudio de tipo descriptivo, que generó la solución al problema de investigación, puesto que se conoció, midió y describió una serie de características de las comunidades de los municipios escogidos.

Respecto al enfoque, la investigación fue mixta. Según Hernández-Sampieri, Fernández-Collado y Baptista-Lucio (1997), este tipo de investigación incluye los enfoques 
cuantitativo y cualitativo. El primer enfoque, o cualitativo, "utiliza la recolección de datos sin medición numérica para descubrir o afinar preguntas de investigación en proceso de interpretación".

Así pues, la investigación cualitativa se desarrolló en Pulí y Chaguaní, donde se utilizaron instrumentos de recolección de datos tales como:

- Observación:

Albert (2006) se refiere a la observación como técnica, pero también como instrumento. Para construir un sistema de observación es necesario definir el universo de aspectos, eventos o conductas que se van a observar; extraer una muestra representativa de tales aspectos; definir las unidades de observación (momentos o indicios, etc.); definir las categorías y subcategorías de observación; seleccionar a los observadores; elegir el medio de observación; elaborar hojas de codificación, codificar y analizar.

Con relación a lo anterior, se utilizó la técnica de observación en áreas sociales y públicas, como parques y plazas, entre otras. Por medio de esta técnica, y mediante el empleo de los diferentes tipos de anotaciones antes mencionadas, se determinaron las características generales sobre la cultura de la comunidad (tradiciones, costumbres, atractivos, hábitos y situación del municipio); este registro se llevó a cabo durante las salidas de campo.

- Entrevista abierta:

Albert (2006) señala que "puede ser de investigación o terapéutica. En general, es una narración conversacional creada conjuntamente por el entrevistador y el entrevistado. En la investigación cualitati- va deben ser flexibles, abiertas, dinámicas, no estructuradas y no estandarizadas".

En las salidas de campo se tuvo en cuenta el siguiente perfil: personas nativas del municipio o que llevaran una pernoctación superior a cinco años, mayores de edad, pertenecientes a una entidad pública/ privada. Lo anterior permitió tener una interacción con personas que conocen aspectos generales del municipio y así lograr conocer a fondo su opinión sobre el desarrollo de una nueva alternativa económica.

- Grupo focal:

Para Albert (2006), es una conversación en grupo con un propósito. Su finalidad es poner en contacto y confrontar diferentes puntos de vista y ayudar a desarrollar más claramente las ideas de todos. Se pueden planear una o varias sesiones.

En efecto, esta técnica se llevó a cabo con los líderes de las juntas de acción comunal de la parte rural y urbana, facilitando así la comunicación de la información acerca del proyecto a las comunidades. Para lograr este acercamiento, se realizó bajo el siguiente proceso: en la alcaldía municipal se solicitó la lista de los líderes, luego se procedió a un contacto vía telefónica para programar una reunión presencial en la que se expusieron el proceso y el proyecto en general, además de abrir un espacio de participación para los líderes por medio de preguntas claves que generaron información fundamental para el proyecto.

Al no tener información sobre el turismo solidario, se decidió investigar si habría una demanda para este y se determinó la necesidad de aplicar encuestas según el perfil del turista solidario establecido por Tejera (2010). Según este autor, “el perfil del viajero solidario español se divide 
según la edad: el primero entre 20 y 35 años y el segundo a partir de 45 años, con un nivel social medio-alto, profesiones liberales, muchas relacionadas con la educación, y 'cierta conciencia social'". De acuerdo con lo anterior, se aplicaron encuestas a la muestra hallada, conformada por 61 personas pertenecientes a dos grupos: voluntariado libertador y comunidad de la red de jóvenes de Cundinamarca de los scouts.

El segundo enfoque utilizado fue de tipo cuantitativo. Según Creswell (2005, citado por Hernández-Sampieri, FernándezCollado y Baptista-Lucio, 1997), "los análisis cuantitativos fragmentan los datos en partes para responder al planteamiento del problema. Tales análisis se interpretan a la luz de las predicciones iniciales (hipótesis) y de estudios previos (teoría)". Con referencia a lo anterior, uno de los instrumentos utilizados fue el generado por el Ministerio de Comercio, Industria y Turismo, denominado "Inventario turístico", por medio del cual se buscó definir los atractivos naturales, culturales, ferias y fiestas de los municipios, calificándolos y mostrando así una oferta para el turismo solidario y comunitario. El otro instrumento empleado fue el conteo de la infraestructura, la superestructura y las facilidades turísticas, que generó información sobre los municipios y sus características para prestar un servicio turístico de calidad.

\section{Resultados}

Al realizar el análisis de la provincia del Magdalena Centro, se distinguen los altos índices de pobreza, como se muestra en la figura 1.

Visto esto, se creó la siguiente tabla teniendo en cuenta las características dadas para el desarrollo del turismo y se preseleccionaron tres municipios, teniendo así una mayor cobertura de la comunidad receptora.

De acuerdo con los análisis efectuados, los municipios seleccionados debían cumplir con los siguientes requisitos:

- Tener un alto índice de pobreza y de esta forma apoyar a la comunidad para superar y cumplir con el objetivo del turismo solidario.

Figura 1. Población pobre por necesidades básicas insatisfechas (NBI) en los municipios de la provincia del Magdalena Centro 1993 vs. 2005

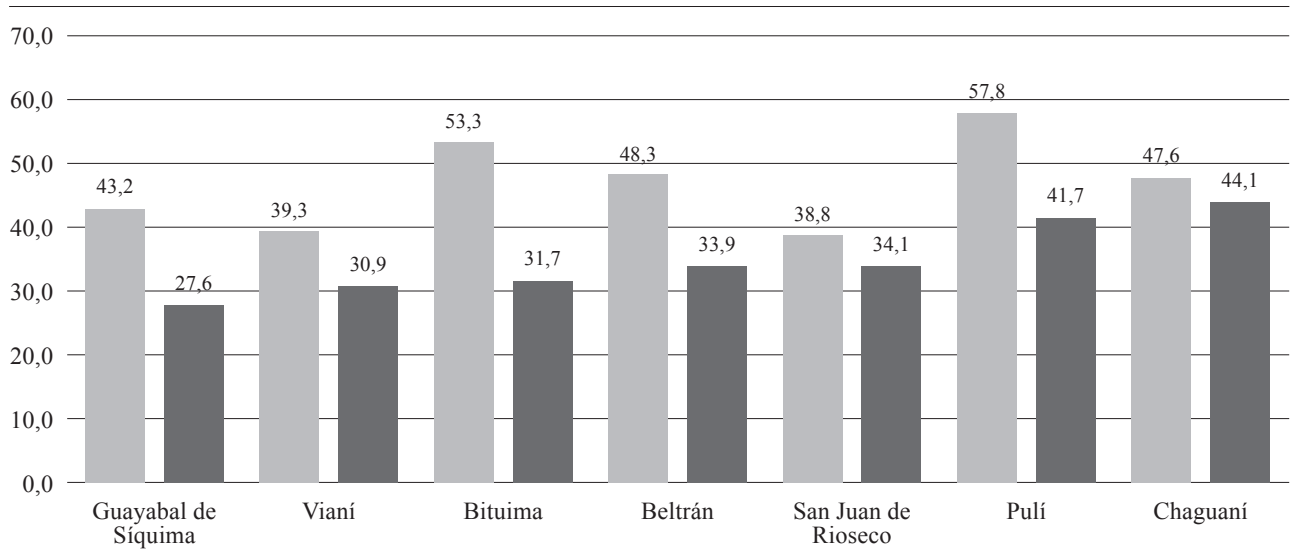

Fuente: Tomado de la Cepec - Universidad del Rosario con datos del DANE (2005) 
Tabla 1. Indicador de elección de municipios

\begin{tabular}{|l|c|c|c|c|l|l|}
\hline $\begin{array}{l}\text { Indicadores } \\
\text { municipios }\end{array}$ & $\begin{array}{c}\text { Atractivos } \\
\text { turísticos }\end{array}$ & $\begin{array}{c}\text { Índice de } \\
\text { pobreza NBI 005 }\end{array}$ & $\begin{array}{c}\text { Obras sociales } \\
\text { por desarrollar }\end{array}$ & $\begin{array}{c}\text { Densidad } \\
\text { poblacional }\end{array}$ & Enfoque turístico & \multicolumn{1}{c|}{ Cercanía } \\
\hline $\begin{array}{l}\text { Guayabal de } \\
\text { Síquima }\end{array}$ & 11 & $27,6 \%$ & Sí & 3.538 habitantes & Turismo de aventura & 1 hora 36 min \\
\hline Bituima & 12 & $31,7 \%$ & Sí & 2.454 habitantes & Turismo sostenible & 1 hora 55 min \\
\hline Vianí & 9 & $30,9 \%$ & Sí & 3.992 habitantes & $\begin{array}{l}\text { Turismo cultural in- } \\
\text { material y agroturismo }\end{array}$ & 2 horas \\
\hline Chaguaní & 15 & $44,1 \%$ & Sí & 3.935 habitantes & $\begin{array}{l}\text { Turismo cultural y } \\
\text { natural }\end{array}$ & 3 horas 18 min \\
\hline $\begin{array}{l}\text { San Juan de } \\
\text { Rioseco }\end{array}$ & 12 & $34,1 \%$ & Sí & 9.462 habitantes & No definido & 2 horas 34 min \\
\hline Pulí & 14 & $41,7 \%$ & Sí & 2.837 habitantes & Turismo natural & 3 horas y 57 min \\
\hline Beltrán & 7 & $33,9 \%$ & Sí & 1.908 habitantes & No definido & 4 horas \\
\hline
\end{tabular}

Fuente: Elaboración propia

- Tener incluidos en sus planes de desarrollo obras sociales a las cuales se pueda vincular al turista y de esta forma crear alianzas con la alcaldía municipal.

- Contar con una densidad poblacional baja y de esta manera tener mayor cobertura y participación de la comunidad, generando así el turismo comunitario.

- Contar con un enfoque turístico para crear una simbiosis respecto al proyecto de turismo solidario y comunitario.

- Contar con la accesibilidad básica, permitiendo así la llegada de los visitantes $\mathrm{y}$ voluntarios.

- Tener una cercanía con Bogotá, abarcando así una mayor demanda.

Esta tabla fue creada según información obtenida de los planes de desarrollo de cada municipio, en los que se establecen estos temas e información secundaria.

Al preseleccionar los municipios de Chaguaní, Pulí y Bituima, se realizaron las salidas de campo por medio de las cuales se levantaron el inventario turístico y el equipamiento turístico. Se realizó un análisis de la información arrojada durante estas salidas, que permitió percibir la aceptación de la comunidad y descartar a Bituima por la falta de interés de la comunidad en actividades turísticas.

Las encuestas realizadas a la demanda obtenida ("voluntariado libertador y la comunidad de la red de jóvenes de Cundinamarca de los Scouts") arrojaron una población interesada por participar en acciones solidarias, teniendo como ventaja conocer los procesos productivos típicos de nuestro país a tan pocas horas.

Se prosiguió con la realización de un análisis FODA, en el que se evidenció la falta de inversión en infraestructuras e incentivación al desarrollo de capacitaciones en aspectos turísticos como nueva alternativa económica por parte de los entes gubernamentales y municipales. Además, se reveló una imagen negativa del territorio por conflictos armados desarrollados en años anteriores, pero teniendo a favor la riqueza cultural y natural que permitiría la llegada de turistas para contribuir económicamente e ir mejorando tal imagen, mostrando un municipio con enfoque turístico. En cuanto a amenazas, se identificaron 
municipios vecinos con productos turísticos similares ya establecidos, por esto es necesario mantener los productos con calidad, para llegar a ser una competencia fuerte para los municipios cercanos.
Por tal razón, se plantearon dos subproductos que permitieran lograr el éxito del proyecto y que resaltaran turísticamente estos municipios. Los subproductos fueron el ecoturismo y el agroturismo.

\section{Primer producto: Eco-Chapulí}

Tabla 2. Clasificación de los atractivos del producto Eco-Chapulí

\begin{tabular}{|c|c|c|c|c|}
\hline Clasificación & Clasificación & Clasificación & Clasificación & Atractivos \\
\hline Tipo de patrimonio & Grupo & Componente & Elemento & Listado principal \\
\hline \multirow{7}{*}{$\begin{array}{l}\text { 2. Sitios } \\
\text { naturales }\end{array}$} & 2.4 Aguas lénticas & 2.4.3 Lagunas & & - Alto de Las lagunas \\
\hline & \multirow[t]{2}{*}{ 2.5 Aguas lóticas } & $\begin{array}{l}\text { 2.5.1 Cascada, catarata } \\
\text { o salto }\end{array}$ & & $\begin{array}{l}\text { - Reserva natural del Salto de } \\
\text { Las Lloviznas } \\
\text { - Balneario natural Las Sardinas }\end{array}$ \\
\hline & & 2.5.4 Quebrada & & $\begin{array}{l}\text { - Quebrada La Vieja } \\
\text { - Puerto Chaguaní }\end{array}$ \\
\hline & $\begin{array}{l}\text { 2.9 Lugares } \\
\text { de observación de } \\
\text { flora y fauna }\end{array}$ & & & $\begin{array}{l}\text { - Mirador casco urbano } \\
\text { - Mirador cerro El Tabor } \\
\text { - Mirador El Boquerón } \\
\text { - Mrador Cerrocón }\end{array}$ \\
\hline & \multirow{2}{*}{$\begin{array}{l}2.10 \text { Áreas prote- } \\
\text { gidas }\end{array}$} & $\begin{array}{l}\text { 2.10.1 Sistema de } \\
\text { Parques Nacionales } \\
\text { Naturales }\end{array}$ & & $\begin{array}{l}\text { - Segunda Reserva Ecológica de } \\
\text { Palmas de Cera } \\
\text { - Reserva Forestal Cerro El Tabor }\end{array}$ \\
\hline & & $\begin{array}{l}\text { 2.10.4 Reservas de la } \\
\text { sociedad civil }\end{array}$ & & Vereda sostenible \\
\hline & $\begin{array}{l}\text { 2.11 Aguas subte- } \\
\text { rráneas }\end{array}$ & 2.11.2 Aguas termales & & Aguas termales \\
\hline
\end{tabular}

Fuente: Elaboración propia.

Tabla 3. Características generales del producto Eco-Chapulí

\begin{tabular}{|l|l|}
\hline \multicolumn{1}{|c|}{ Nombre del producto } & \multicolumn{1}{c|}{ Eco-Chapuli } \\
\hline Objetivo del producto & $\begin{array}{l}\text { Dar a conocer los municipios de Pulí y Chaguaní como referentes ecoturísticos de la } \\
\text { provincia de Magdalena Centro, aprovechando su riqueza natural. }\end{array}$ \\
\hline Beneficios funcionales & $\begin{array}{l}\text { Alimentos y bebidas } \\
\text { Alojamiento }\end{array}$ \\
\hline Beneficios simbólicos & $\begin{array}{l}\text { Emociones y realización personal, posibilidad amplia de que el visitante descubra la } \\
\text { riqueza natural mientras apoya obras que beneficien a estas comunidades. }\end{array}$ \\
\hline Beneficios vivenciales & $\begin{array}{l}\text { Posibilidad de acceso a la comunidad por medio de un alojamiento y alimentación } \\
\text { con el toque local. Realización de actividades que permitan el contacto con la natu- } \\
\text { raleza. }\end{array}$ \\
\hline
\end{tabular}




\begin{tabular}{|c|c|}
\hline Nombre del producto & Eco-Chapuli \\
\hline Servicios básicos & $\begin{array}{l}\text { Contacto con la naturaleza } \\
\text { Alojamiento rural } \\
\text { Actividades ecoturísticas }\end{array}$ \\
\hline $\begin{array}{l}\text { Servicios complemen- } \\
\text { tarios }\end{array}$ & $\begin{array}{l}\text { Transporte } \\
\text { Información } \\
\text { Actividades artísticas y culturales }\end{array}$ \\
\hline $\begin{array}{l}\text { Aspectos físicos y ma- } \\
\text { teriales }\end{array}$ & $\begin{array}{l}\text { Casas rurales } \\
\text { Tiendas } \\
\text { Fincas } \\
\text { Folletos promocionales } \\
\text { Gastronomía local } \\
\text { Miradores } \\
\text { Recursos naturales (lagunas, ríos, termales) }\end{array}$ \\
\hline Personal de contacto & $\begin{array}{l}\text { Guías turísticos locales } \\
\text { Dueños de las fincas y casas rurales } \\
\text { Expresos }\end{array}$ \\
\hline Turista & $\begin{array}{l}\text { Usuarios (visitantes, turistas y residentes) con interés por el cuidado de los recursos } \\
\text { naturales }\end{array}$ \\
\hline
\end{tabular}

Fuente: Elaboración propia.

\section{Segundo producto: Agro-Cafeca}

Tabla 4. Clasificación de los atractivos del producto Agro-Cafeca

\begin{tabular}{|c|c|c|c|c|}
\hline $\begin{array}{l}\text { Primer nivel de } \\
\text { clasificación }\end{array}$ & $\begin{array}{l}\text { Segundo nivel de } \\
\text { clasificación }\end{array}$ & $\begin{array}{l}\text { Tercer nivel de } \\
\text { clasificación }\end{array}$ & $\begin{array}{l}\text { Cuarto nivel de } \\
\text { clasificación }\end{array}$ & Atractivos \\
\hline Tipo de patrimonio & Grupo & Componente & Elemento & Listado principal \\
\hline $\begin{array}{l}\text { 1. Patrimonio } \\
\text { cultural }\end{array}$ & $\begin{array}{l}\text { 1.1 Patrimonio cultu- } \\
\text { ral material inmueble; } \\
\text { grupo arquitectónico }\end{array}$ & $\begin{array}{l}\text { 1.1.2 Arquitectura } \\
\text { habitacional }\end{array}$ & & $\begin{array}{l}\text { 1.1.2.2 Vivienda rural. } \\
\text { Casas de producción } \\
\text { panelera, cafetera y con } \\
\text { siembra de caucho. }\end{array}$ \\
\hline $\begin{array}{l}\text { 1.6 Patrimonio } \\
\text { cultural inmaterial }\end{array}$ & $\begin{array}{l}\text { 1.6.3 Lenguas y } \\
\text { expresiones orales } \\
\text { 1.6.6 Expresiones } \\
\text { musicales y sonoras }\end{array}$ & & & $\begin{array}{l}\text { - Encuentro Cultural y } \\
\text { Homenaje al Campesino } \\
\text { Chaguariceño } \\
\text { - Ferias y fiestas del } \\
\text { municipio }\end{array}$ \\
\hline \multirow{2}{*}{$\begin{array}{l}\text { 1.7 Festividades y } \\
\text { eventos }\end{array}$} & $\begin{array}{l}\text { 1.7.1.1 Aniversarios } \\
\text { de fundación y/o Fies- } \\
\text { tas del Retorno }\end{array}$ & & & $\begin{array}{l}\text { Ferias y fiestas del mu- } \\
\text { nicipio }\end{array}$ \\
\hline & $\begin{array}{l}\text { 1.7.2 Ferias y exposi- } \\
\text { ciones }\end{array}$ & $\begin{array}{l}\text { 1.7.2.1 Agrícola } \\
\text { 1.7.2.7 Equina } \\
\text { 1.7.2.8 Ganadera } \\
\text { 1.7.2.9 Gastronómica }\end{array}$ & & $\begin{array}{l}\text { Ferias y fiestas del mu- } \\
\text { nicipio }\end{array}$ \\
\hline
\end{tabular}

Fuente: Elaboración propia. 
Tabla 5. Características generales del producto Agro-Cafeca

\begin{tabular}{|l|l|}
\hline \multicolumn{1}{|c|}{ Nombre del producto } & \multicolumn{1}{c|}{ Agro-Cafeca } \\
\hline Objetivo del producto & $\begin{array}{l}\text { Dar a conocer los municipios de Pulí y Chaguaní como referentes agroturísticos de la } \\
\text { provincia de Magdalena Centro, aprovechando su agricultura artesanal. }\end{array}$ \\
\hline Beneficios funcionales & $\begin{array}{l}\text { Alimentos y bebidas } \\
\text { Alojamiento }\end{array}$ \\
\hline Beneficios simbólicos & $\begin{array}{l}\text { Emociones y realización personal, posibilidad amplia de que el visitante participe en } \\
\text { los procesos de producción agrícola y en obras que beneficien a estas comunidades. }\end{array}$ \\
\hline Beneficios vivenciales & $\begin{array}{l}\text { Posibilidad de acceso a la comunidad por medio de un alojamiento y alimentación } \\
\text { con el toque local. Realización de actividades que permitan un acercamiento a la } \\
\text { principal actividad económica del territorio. }\end{array}$ \\
\hline Servicios básicos & $\begin{array}{l}\text { Participación en las actividades agropecuarias de la comunidad (sembrado de café, } \\
\text { molienda en entable, etc.). } \\
\text { Alojamiento y alimentación local. }\end{array}$ \\
\hline $\begin{array}{l}\text { Servicios complemen- } \\
\text { tarios }\end{array}$ & $\begin{array}{l}\text { Transporte } \\
\text { Información } \\
\text { Actividades artísticas, culturales y naturales. }\end{array}$ \\
\hline
\end{tabular}

Fuente: Elaboración propia.

\section{Estrategias y programas planteados para desarrollar los productos con éxito}

Tabla 6. Estrategias, programas y actividades para la implementación del producto de naturaleza

Estrategia 1: Adecuar y mejorar las potencialidades turísticas

1. Programa para la selección de los atractivos, la infraestructura turística y la comunidad que va a participar.

Actividades:

- Reunión con la Junta de Acción Comunal, que será la encargada de llevar a cabo el proyecto con ayuda de entes públicos y privados si la requieren.

- La Junta de Acción Comunal identificará a los interesados en participar y las potencialidades turísticas que se van a tratar.

- Elaboración de una base de datos de los prestadores de servicio para su posterior promoción regional y nacional.

- Definición de condiciones y requisitos de los atractivos para la prestación de servicio del ecoturismo y el agroturismo.

2. Programa para el mejoramiento de los atractivos seleccionados y planta turística.

Actividades:

- Apoyo de los entes gubernamentales y de inversionistas para la adecuación de los atractivos.

- Apoyo de mano de obra por organizaciones sin ánimo de lucro para colaboración en obras que la comunidad necesite.

- Organización de la Junta de Acción Comunal para establecer recursos y actividades para la adecuación de los atractivos (señalización turística, senderos, etc.).

- Organización de un lugar adecuado para la llegada del transporte de los visitantes. 
Estrategia 2: Efectuar acciones para desarrollar el turismo de naturaleza

1. Programa de desarrollo de un producto ecoturístico.

Actividades:

- Creación de un inventario de las aves nativas y exóticas del lugar.

- Creación de un inventario de los animales silvestres del lugar.

- Creación de un inventario de flora del lugar.

2. Programa de desarrollo de un producto agroturístico.

Actividades:

- Búsqueda de lineamientos para la prestación del servicio de alojamiento rural (Norma técnica sectorial NTSH 008:2006. Alojamientos rurales, requisitos de planta y servicio) (ICONTEC y Cotelco, 2006).

- Adecuación de las viviendas según el lineamiento anterior.

Estrategia 3: Desarrollar el turismo comunitario y solidario en el territorio

1. Programa de análisis de los lineamientos nacionales de turismo comunitario.

Actividades:

- Solicitud a los entes departamentales para recibir asistencia técnica referente a iniciativas de turismo comunitario.

- Identificación de fuentes de cooperación para el desarrollo del turismo comunitario.

- Plasmar las actividades necesarias para establecer el territorio como un destino de turismo comunitario.

- Gestión de proyectos en los que puedan participar visitantes voluntarios.

- Establecimiento de tarifas llamativas para visitantes voluntarios.

Estrategia 4: Fortalecer las habilidades y competencias del talento humano del territorio en lo referente al turismo

1. Programa municipal de capacitaciones para la gestión del turismo.

Actividades:

- Creación de convenios con entidades educativas como el SENA para generar cursos necesarios para prestar un servicio de calidad en función de las necesidades de la demanda turística y la generación de empleo en el territorio.

- Creación de un convenio con la CAR para cursos de reconocimiento y cuidado de flora y fauna del territorio.

- Campaña para el desarrollo empresarial en turismo por medio de la Política Nacional de Emprendimiento Turístico.

- Gestión de convenios para cursos de emprendimiento para la comunidad.

Estrategia 5: Incentivar la aplicación de certificaciones

1. Programa de reconocimiento de las certificaciones.

Actividades:

- Jornadas de información para certificaciones (calidad turística, establecimientos de alojamiento y alimentación, etc.), requisitos y beneficios.

- Apoyo de los entes gubernamentales para ofrecer un servicio de asesoría y seguimiento a los prestadores turísticos.

Estrategia 6: Implementar estrategias de seguridad para los visitantes en el territorio

1. Programa de seguridad del territorio.

Actividades:

- Implementación de Programa de Policía de Turismo. 
- Campañas de sensibilización por medio de las cuales se explique todo acerca de la llegada de un visitante y los requerimientos para prestar un servicio de calidad.

2. Programa de turismo responsable y sostenible.

Actividades:

- Jornadas de revisión del cumplimiento del Programa de Prevención de la Explotación Sexual, de Niños, Niñas y Adolescentes.

- Actividades para la prevención del consumo de sustancias psicotrópicas en las prácticas turísticas.

- Actividades para fomentar el cuidado y la conservación de recursos naturales.

Estrategia 7: Consolidar estrategias de promoción y comercialización lideradas por la Junta de Acción Comunal

1. Programa de aplicación de la Política de Promoción y Mercadeo del Turismo.

Actividades:

- Diseño de acciones que permitan dar a conocer los productos turísticos del territorio apoyados por la alcaldía municipal.

- Implementación de estrategias de mercadeo según la estacionalidad del territorio, fomentando un turismo fluente.

2. Programa de comercio electrónico.

Actividades:

- Actualización de información turística en la página web de la alcaldía municipal.

- Creación de página web en la que se muestre la riqueza turística del territorio, enlazada con redes sociales.

3. Plan de evaluación

Actividades:

- Realización de un plan de seguimiento y evaluación de resultados de las actividades de promoción turística regional para generar una retroalimentación.

Estrategia 8: Diseñar paquetes turísticos enfocados en turismo solidario y comunitario

1. Programa de desarrollo de los posibles paquetes turísticos en el territorio.

Actividades:

- Selección de las actividades con relación al turismo solidario y comunitario desarrollado y liderado por la comunidad, así como también establecimiento del tiempo y de las tarifas según preferencias del turista.

2. Programa de comercialización de paquetes turísticos.

Actividades:

- Búsqueda de apoyo de la alcaldía y de inversionistas para la comercialización y promoción de los paquetes.

- Convenio con agencias de viajes que apoyen iniciativas de la comunidad y que faciliten la comercialización de los paquetes.

Fuente: Elaboración propia.

La información previamente presentada se obtuvo como resultado final de la investigación y arrojó la alta probabilidad de desarrollar una nueva alternativa económica en estos municipios. Esta investigación puede ser llevada a la práctica en otros municipios del país, para superar así los altos índices de pobreza acompañados de desempleo y emigración por parte de la población.

\section{Conclusiones}

El trabajo con la población campesina de Colombia permitió observar cómo los campesinos tienen los mayores índices de pobreza en el país a pesar de su gran riqueza cultural y natural y de contar con potencialidades turísticas con tendencia al éxito. Por lo anterior, se planteó el desarrollo de un turismo con 
enfoque dirigido al turismo comunitario y solidario, en el que la misma comunidad sea la encargada de recibir, acoger y mostrar al posible visitante algo que para ella es normal, ya que se trata de su diario vivir, pero que para aquella persona que llega será algo poco habitual y sorprendente, que le permitirá conocer otra cultura, tradiciones, saberes culinarios y riqueza natural ajenas a su cultura. Por tal motivo, se espera que esta actividad le ofrezca al campesinado el turismo como alternativa económica sustentable para el territorio.

Por consiguiente, durante el desarrollo del producto turístico se evidenciaron las iniciativas e ideas que la población tanto rural como del casco urbano tienen para mejorar su calidad de vida e incluirse en un nuevo tipo de desarrollo social y económico. Pero, por cuestiones de desinformación y falta de apoyo de los entes gubernamentales o de entidades educativas, estas iniciativas se quedan solo en ideas sin fundamento y sin su ejecución; es por esto que, por medio de las estrategias y los programas propuestos, la población debe generar una idea para empezar a plasmar el turismo en su municipio.

Debido a que hoy en día las tendencias nacionales e internacionales han cambiado y muestran un perfil de turista que busca una variedad de destinos, no solo sol y playa o momentos de quietud y relajación, sino que, por el contrario, busca lugares naturales donde pueda estar activo durante su tiempo de ocio y adquirir nuevos aprendizajes en situaciones diferentes y experienciales como, por ejemplo, el proceso de producción del café y de panela, entre otros, la comunidad debe aprovechar esa nueva tendencia del turista y ofrecer un destino agroturístico a tan pocas horas de Bogotá.

Así mismo, el análisis de los resultados de las encuestas aplicadas a la demanda demostró que existe una población en Cundinamarca que busca desarrollar acciones de voluntaria- do para su realización personal ejecutando un turismo comunitario, es decir, el desarrollo de obras sociales, y que al mismo tiempo intenta conocer a fondo a la comunidad, donde estos mostrarán su riqueza cultural y natural. Así se establece que en Pulí y Chaguaní existen diferentes procesos agrícolas que son atractivos para esta demanda, además de su riqueza natural sin explotar.

También se evidenció la pérdida de algunos elementos culturales por diferentes circunstancias, tanto internas como externas, como el conflicto armado que se desarrolló en la zona, el cual generó un desplazamiento forzado de la población y causó así la pérdida de los saberes ancestrales en cuanto a artesanías y saberes culinarios de la cultura de los panches, ancestros de muchos de los habitantes del municipio de Pulí.

Adicional a lo anterior, la imagen negativa que se tiene de los municipios por los conflictos armados ocurridos hasta el año 2002 llegó a afectar a la comunidad, ya que evitó la expansión del mercado referente a sus actividades económicas principales (producción de café y panela, etc.). Por esa razón, por medio del turismo y la llegada de visitantes, se busca mostrar la realidad de los municipios y generar de esta manera una promoción voz a voz que, además de crear una nueva alternativa económica, fortalezca las existentes.

Con referencia a lo anterior y a la confirmación de la riqueza cultural y natural existente en Pulí y Chaguaní, se establecieron dos subproductos para los cuales se tomaron las potencialidades turísticas de los municipios, incorporando a la población y permitiéndole obtener un beneficio a corto plazo, referido al aporte económico que dejará el visitante. A largo plazo, en obras sociales, además de cambiar la imagen de forma positiva, se requiere generar un aporte económico y nuevas alternativas laborales. 
El desarrollo de un producto de turismo de naturaleza con gestión del turismo solidario y comunitario permite dar a conocer y ayudar al reconocimiento del territorio, además de ayudar a las poblaciones en situación de pobreza por medio de nuevas alternativas económicas e incentivando la conservación y preservación de la cultura.

Si se gestiona y se lleva a cabo la implementación de estos productos turísticos llevándolos a un paquete turístico con base en lo investigado, seguido de su promoción y comercialización, los municipios serán vistos como destinos turísticos del departamento propicios para visitar.

Figura 2. Fotografías tomadas durante las salidas de campo

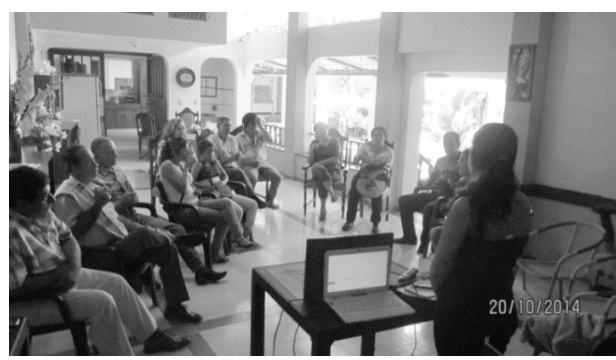

Exposición del proyecto por parte de las estudiantes y el profesor en Chaguaní.

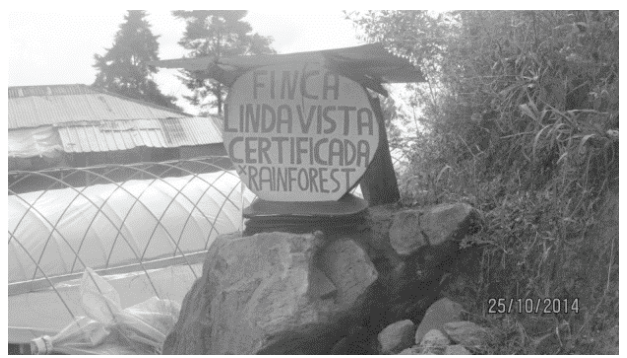

Cultivo de plátano en la finca Linda Vista, Chaguaní.

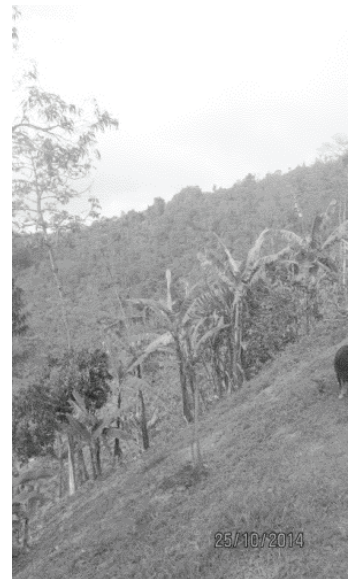

Exposición del proyecto por parte de las estudiantes en Pulí.

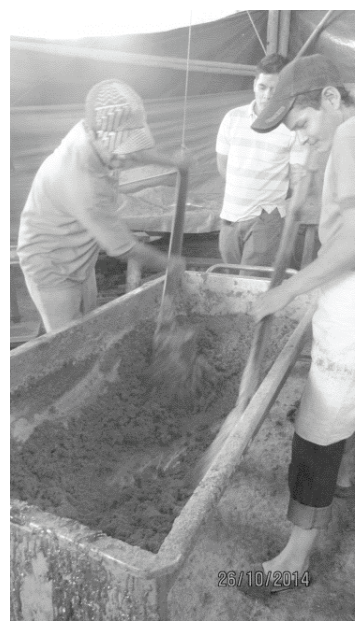

Proceso de polvorización de la panela.

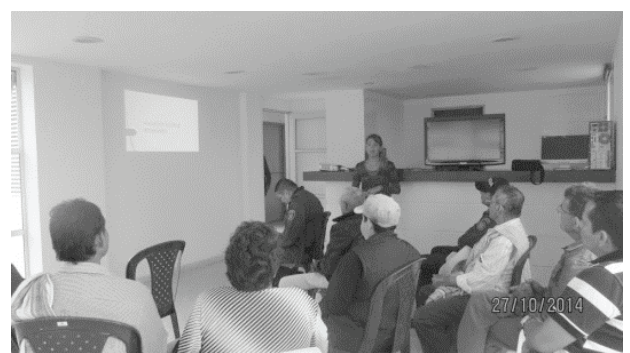

Reunión de los líderes comunales en la estación de policía del municipio de Pulí. 


\section{Referencias bibliográficas}

Albert Gómez, M. J. (2006). La investigación educativa: claves teóricas. España: McGraw-Hill Interamericana de España.

Alcaldía de Chaguaní - Cundinamarca. (7 de julio de 2014). Nuestro municipio. Recuperado de goo.gl/XB1F3G

Alcaldía de Pulí - Cundinamarca. (12 de noviembre de 2014). Nuestro municipio. Recuperado de goo.gl $/ \mathrm{mWKc} 5 \mathrm{E}$

Bitsintos, K. (s. f.). Social tourism and finish line promo codes: My secret to traveling cheap. Recuperado de http://www.bits-int.org/

Cañamas, M. (2011). Turismo solidario por medio del deporte y la recreación. Medellín: Universidad de Antioquia. Recuperado de goo.gl/mrv9hZ

Concejo Municipal - Municipio de Pulí. (31 de mayo de 2012). Acuerdo n. ${ }^{\circ}$ 009. Por medio del cual se adopta el Plan de Desarrollo del Municipio de Pulí Cundinamarca 2012-2015 y se dictan otras disposiciones. Recuperado de http://cdim. esap.edu.co/BancoMedios/Documentos\%20PDF/ puli-pd-2012-2015.pdf

Departamento Administrativo Nacional de Estadística - DANE. (4 de septiembre de 2013). Pobreza monetaria y multidimensional (Comunicado de prensa). Recuperado de goo.gl/QwOvCz

. (2 de enero de 2013). Cundinamarca: Pobreza monetaria 2011 (Boletín de prensa). Recuperado de goo.gl/FhRjVq

Fernández, V. R. (marzo de 2006). Diseño del producto turístico -un enfoque y una propuesta metodológica-. Recuperado de goo.gl/zRB9e1

Gómez, E. G. (23 de enero de 2014). Turismo de voluntariado (Trabajo de grado). Escuela Universitaria de Educación y Turismo, Universidad de Salamanca, Salamanca, España. Recuperado de goo.gl/sU4sjy

Hernández-Sampieri, R., Fernández-Collado, C. y Baptista-Lucio, P. (1997). Metodología de la investigación. Bogotá: McGraw-Hill Interamericana - Panamericana Formas e Impresos S. A. Recuperado de goo.gl/b4iiFo

Icontec y Cotelco. (2006). Norma técnica sectorial NTSH 008. Alojamientos rurales, requisitos de planta y servicio. Bogotá: Autores. Recuperado de goo.gl/Q3rJiO

López-Guzmán, T. y Sánchez, S. M. (2009). Turismo comunitario y generación de riqueza en países en vías de desarrollo. Un estudio de caso en El Salvador. REVESCO, 99, 85-103. Recuperado de goo.gl/B5Y22D

López-Guzmán, T. J., Vásquez, G. y Melián, A. (2007). Turismo solidario. Una perspectiva desde la Unión Europea. Gestión Turística, 8, 85-104. Recuperado de goo.gl/sYf1DR

Ministerio de Comercio, Industria y Turismo MinciT. (julio de 2011). Lineamientos de política para el desarrollo del turismo comunitario en Colombia. Bogotá: Autor. Recuperado de goo. g1/6GFGsv

(septiembre de 2012). Politica de turismo de naturaleza (Documento preliminar). Bogotá: Autor. Recuperado de goo.gl/4NL8ty

Ministerio de Comercio, Industria y Turismo y Fontur. (2016). Plan Sectorial de Turismo "Turismo para la construcción de la paz” 2014-2018. Bogotá D. C.: Mincit y Fontur. Recuperado de goo.gl/eMMftC

Pingel, C. (agosto de 2007). Turismo solidario en el marco del turismo responsable. Contextos, conceptos y aplicaciones (Monografía de graduación). Universidad Nacional de Mar del Plata, Mar del Plata, Argentina. Recuperado de goo.gl/rjAums 
Taylor, S. y Bogdan, G. (2000). Introducción a los métodos cualitativos de investigación ( $3 .^{\mathrm{a}} \mathrm{ed}$.). México: Paidós Básica.

Tejera, J. (10 de octubre de 2010). El turismo solidario motiva cada vez más nuestros viajes. Ecoturismo. Recuperado de goo.gl/csOgIY

Universidad del Rosario y Gobernación de Cundiamarca. (2011). Planes de competitividad y desarrollo económico incluyente en cinco provincias de Cundinamarca. Bogotá: Universidad del Rosario.

Wikipedia. (s. f.). Provincias de Cundinamarca. Recuperado de goo.gl/WF9Mep . (s. f.). Provincia de Magdalena Medio. Recuperado de goo.gl/hM0egI 